\title{
Effect of Table Tennis Training Program on Sustained Attention and Cognitive Flexibility of Children with Developmental Coordination Disorder
}

\section{Mohammad Jalilvand}

Department of Physical Education and Sports Sciences, Faculty of Humanities, Kermanshah Branch, Islamic Azad University, Kermanshah, Iran

\section{ABSTRACT}

Introduction: In addition to coordination and motor difficulties, one of the main problems in children with developmental coordination disorder that prevents them from learning in early childhood education is a defect in executive functions. In recent years, the tendency to use novel therapeutic approaches for children with executive dysfunctions has increased. Cognitive rehabilitation or training in executive functions is an approach that has received much attention in recent years. The purpose of the present study was to investigate the effect of the Table Tennis Training Program on sustained attention and cognitive flexibility in children with developmental coordination disorder. Materials and Methods: The research method was quasi-experimental with a pretes t-posttest design. The statistical population of this study was all children aged 9-12 years with developmental coordination disorder in Kermanshah, Iran. Subjects in this study were 20 children with developmental coordination disorder who were selected by convenience sampling and were randomly assigned into two control and experimental groups. The tools of this study were Wilson Developmental Coordination Disorders Questionnaire, Movement Assessment Buttery for Children, Computerized Continuous Performance, and Wisconsin Card Sorting Test. Before and after the intervention program, sustained attention and cognitive flexibility of all subjects were measured. Table Tennis Training Program was held in the gym for 12 weeks and twice a week for 70 minutes. Results: The results showed a significant improvement in sustained attention and cognitive flexibility in children with developmental coordination disorder following 12 weeks of Table Tennis Training. Conclusion: Table tennis training has improved sustained attention and cognitive flexibility in children with developmental coordination disorder. These data suggest the benefits of exercise programs based on Training of executive functions and high attentional load in children with coordination disorder.

\section{Keywords:}

1. Motor Skills Disorders

2. Executive Function

3. Exercise

*Corresponding Author: Mohammad Jalilvand 


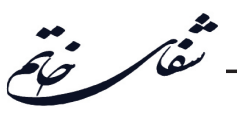

اثربخشى برنامذٔ آموزش تنيس روى ميز بر توجه يايدار و انعطاف يذيرى شناختى كودكان داراى اختلال هماهنگى رشدى

\author{
محمد جليلوند
}

كروه تربيت بدنى و علوم ورزشى، دانشكده علوم انسانى، واحد كرمانشاه، دانشكاه آزاد اسلامى، كرمانشاه، ايران

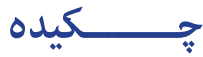

مقدمه: علاوه بر مشكلات هماهنگى و حركتى، يكى از مشكلات اساسى كودكان داراى اختلال هماهنكى

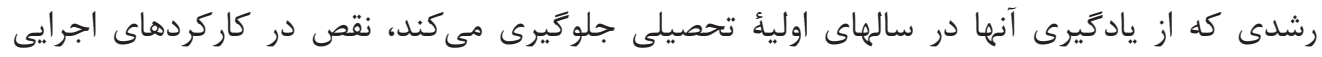

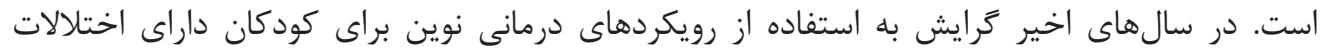

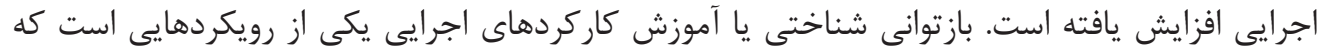

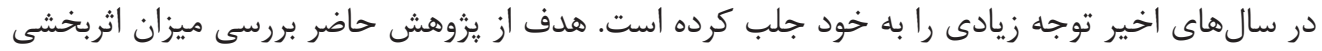

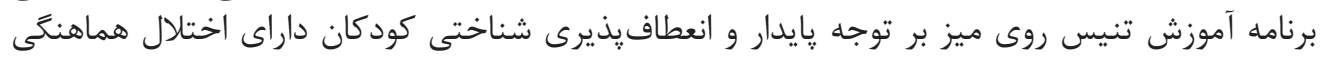

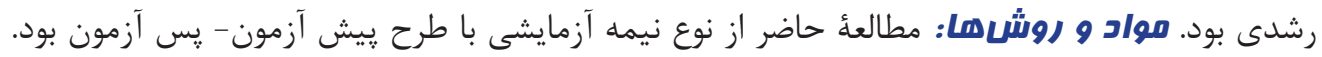

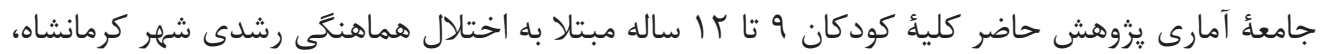

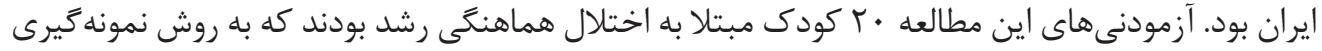

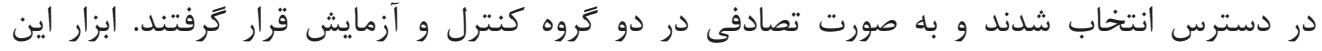

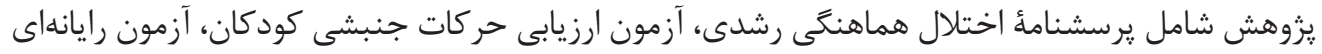

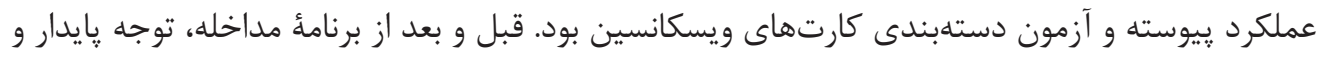

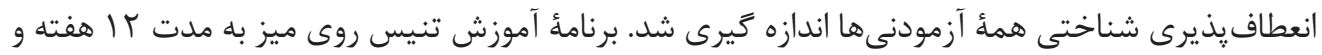

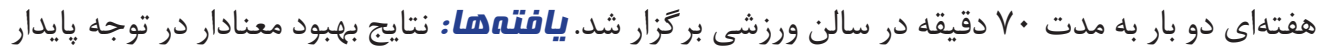

وازههاى كليدى:

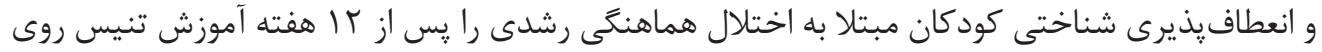

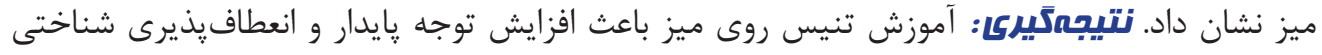

: اخت

حتى

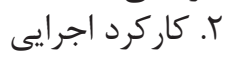

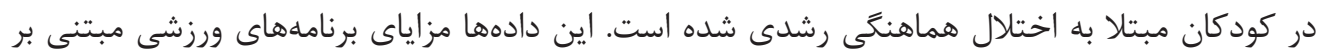
r 


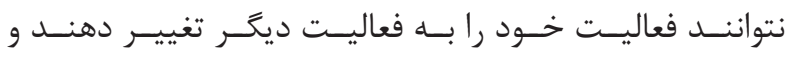

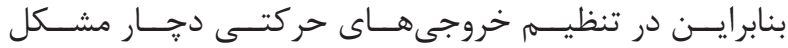

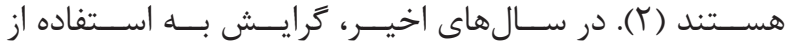

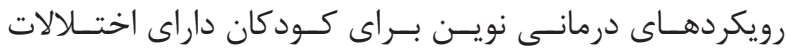

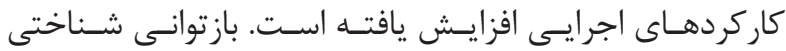

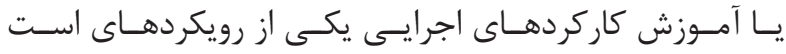

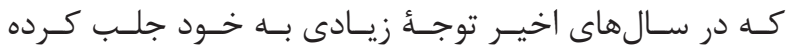

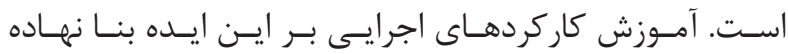

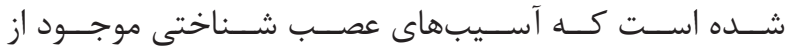

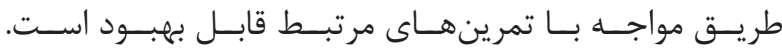

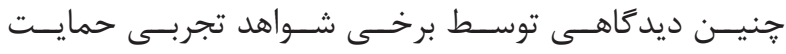

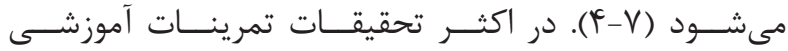

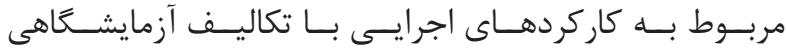

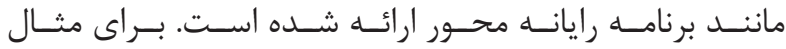

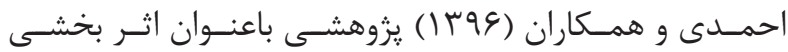

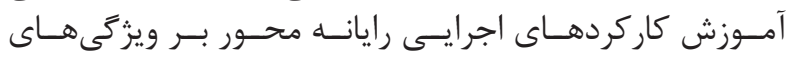

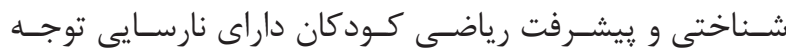

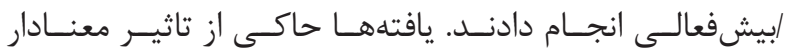

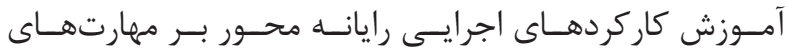

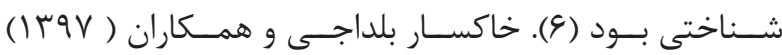

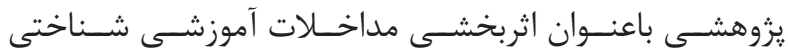

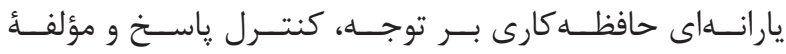

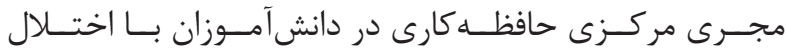

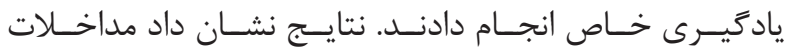

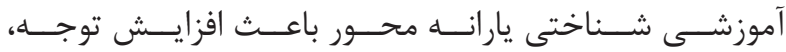

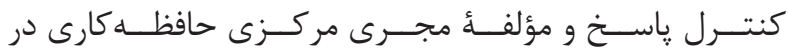

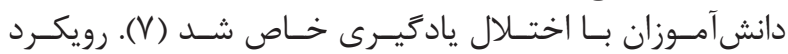

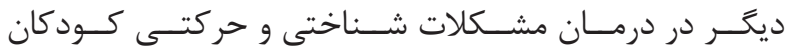

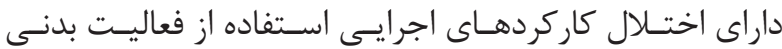

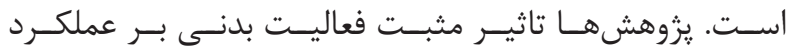

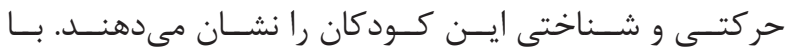

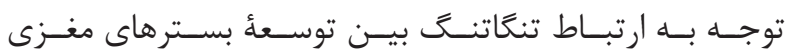

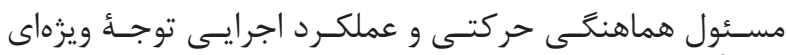

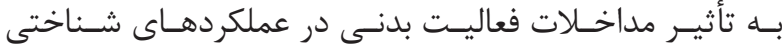

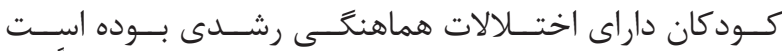

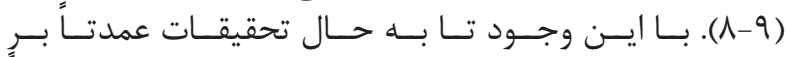

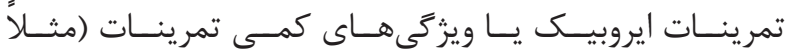

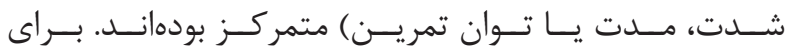

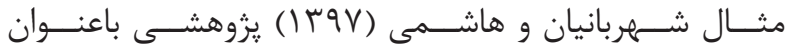

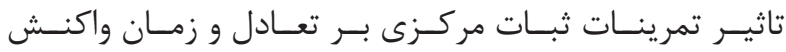

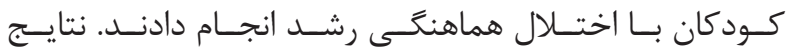

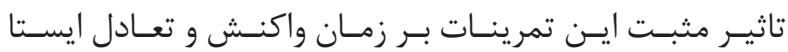

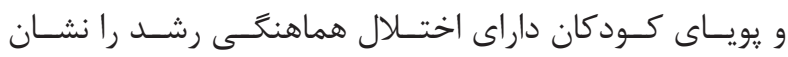

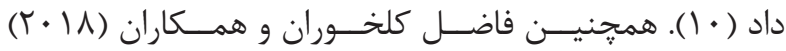

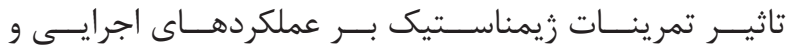

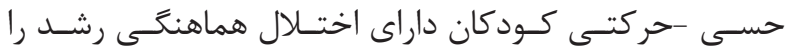

${ }^{1}$ Developmental Coordination Disorder; DCD

${ }^{2}$ Executive Function

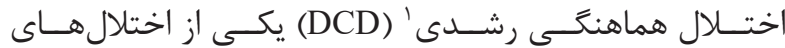

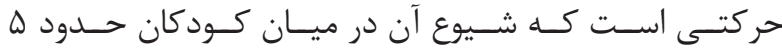

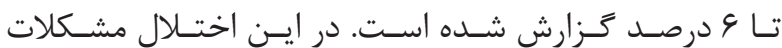

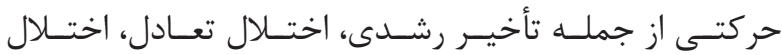

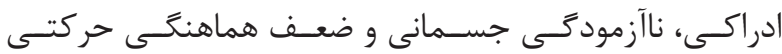

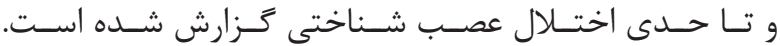

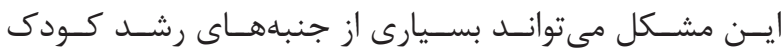

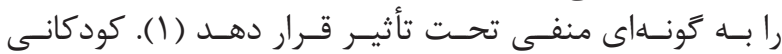

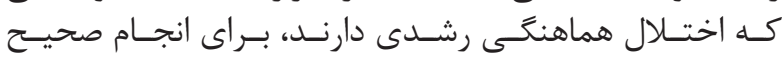

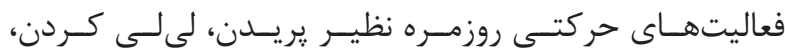

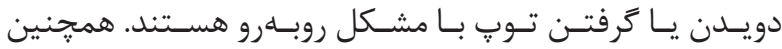

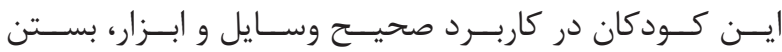

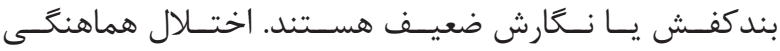

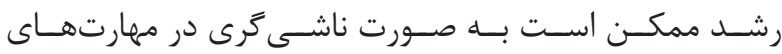

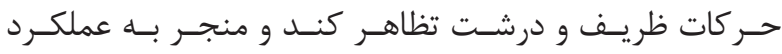

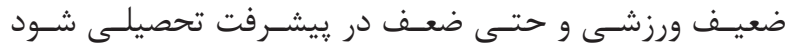

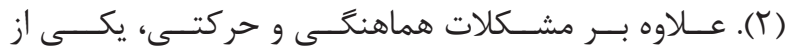

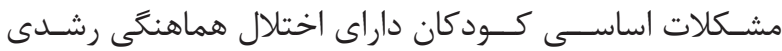

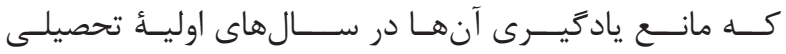

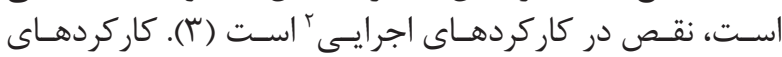

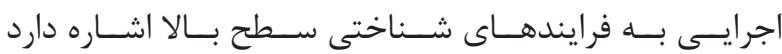

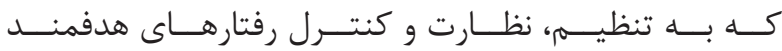

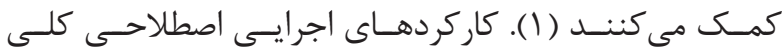

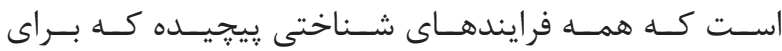

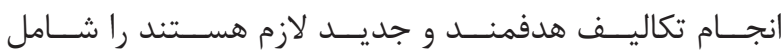

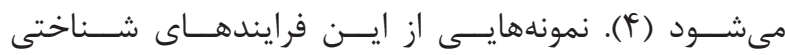

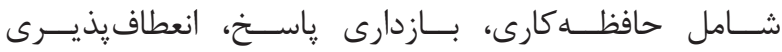

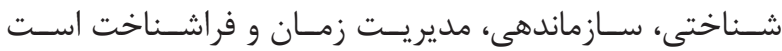

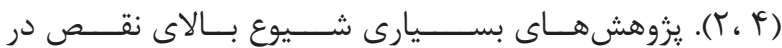

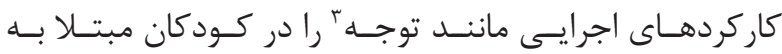

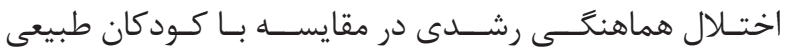

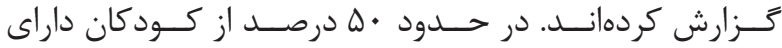

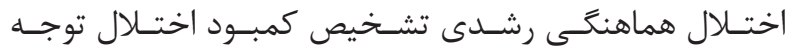

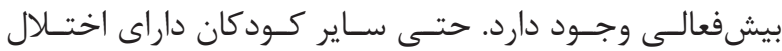

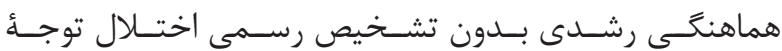

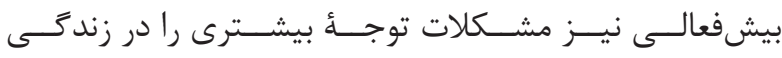

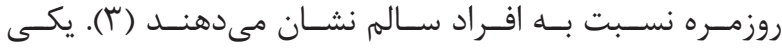

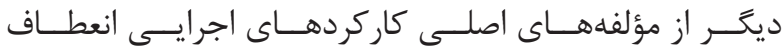

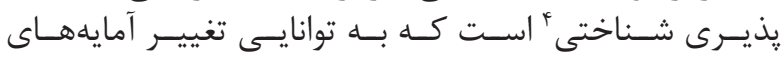

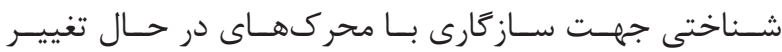

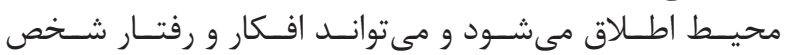

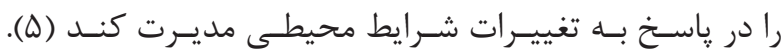

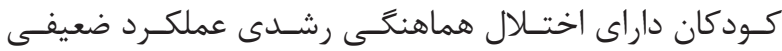

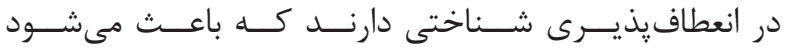

\footnotetext{
${ }^{3}$ Attention

${ }^{4}$ Cognitive Flexibility
} 


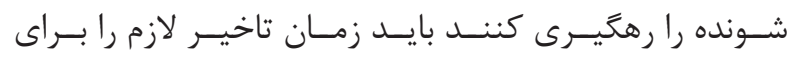

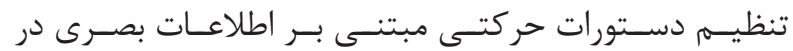

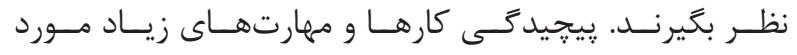

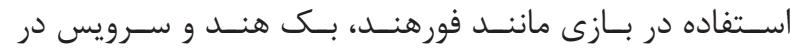

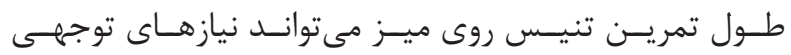

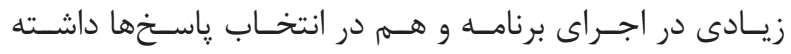

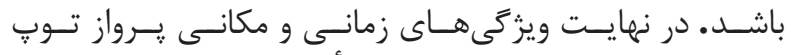

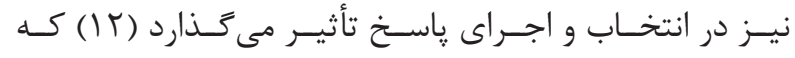

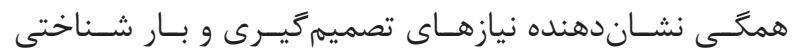

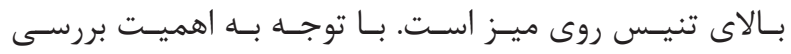

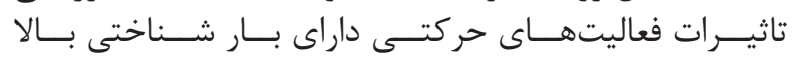

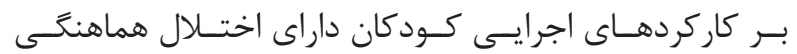

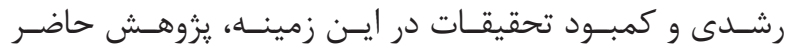

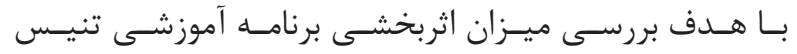

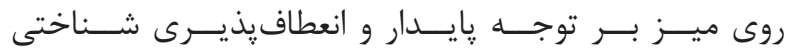

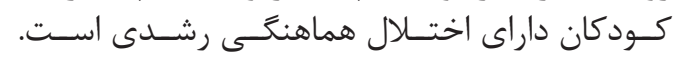

مواد و روشها

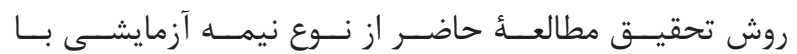

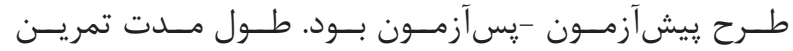

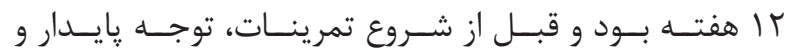

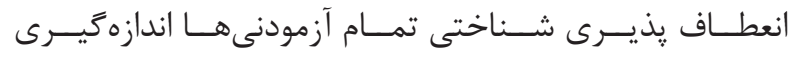

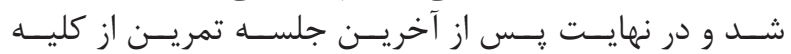

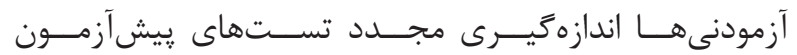

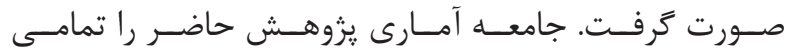

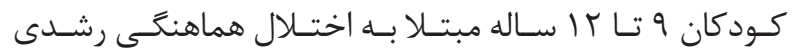

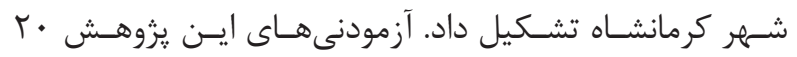

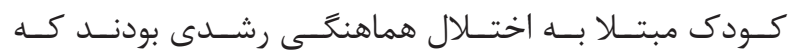

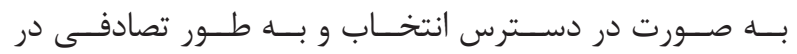

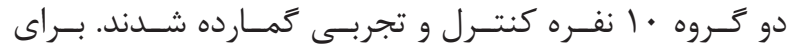

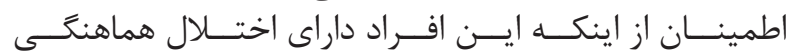

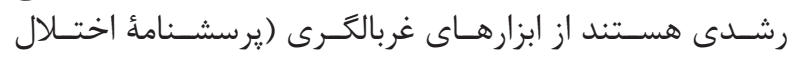

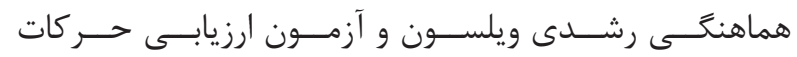

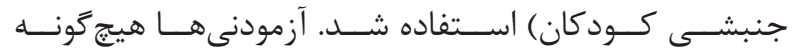

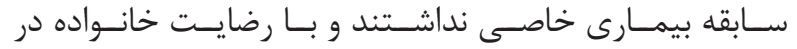

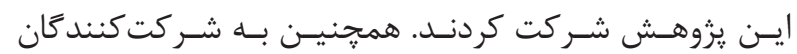

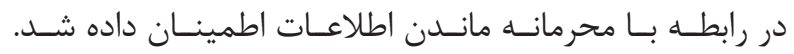

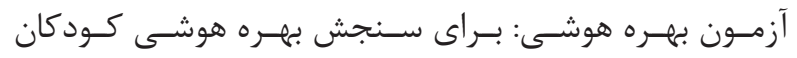

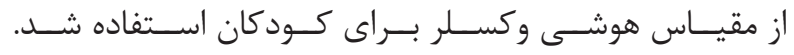

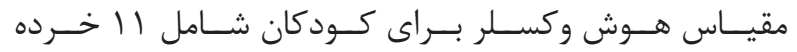

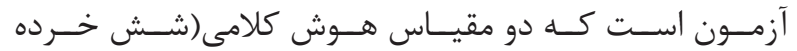

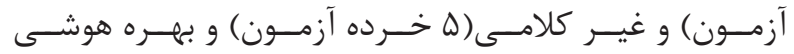

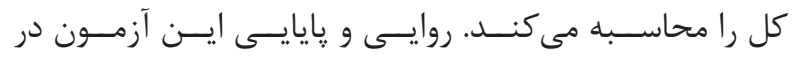

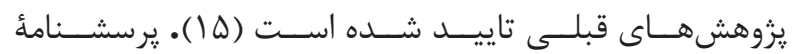

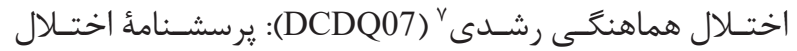

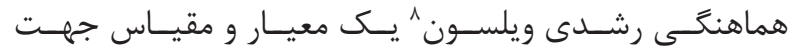

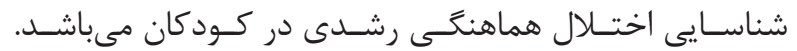

${ }^{5}$ Visual smooth pursuit

${ }^{6}$ Predictive control mechanism

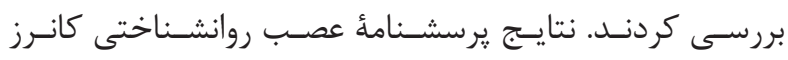

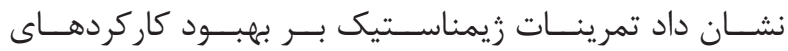

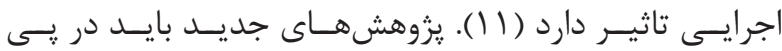

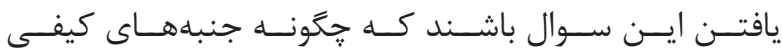

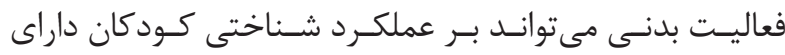

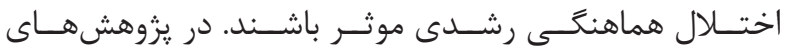

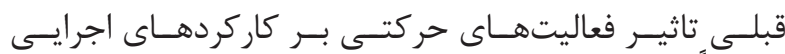

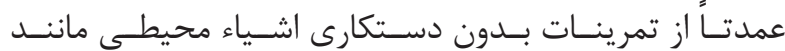

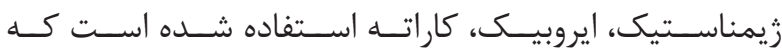

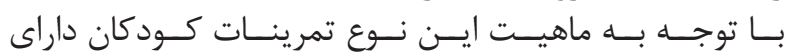

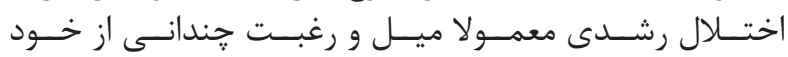

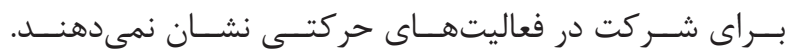

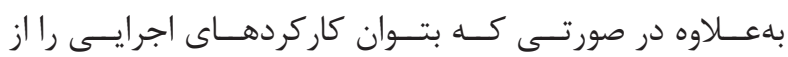

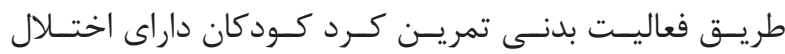

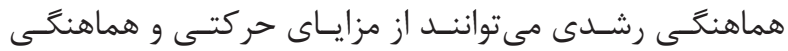

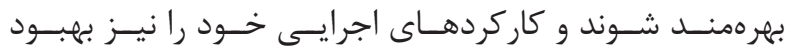

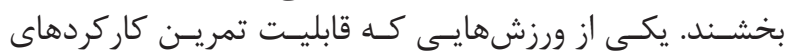

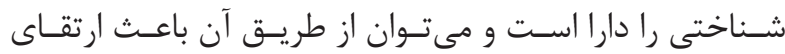

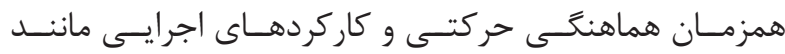

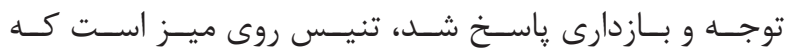

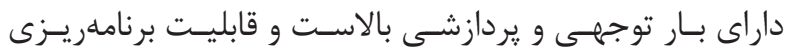

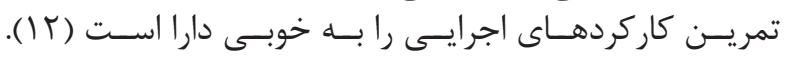

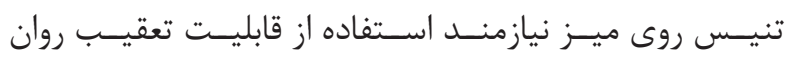

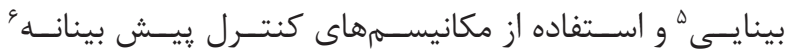

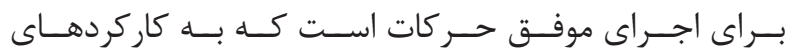

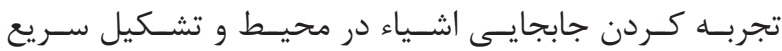

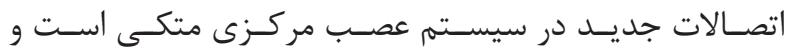

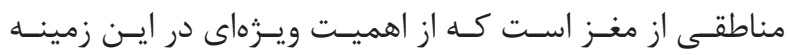

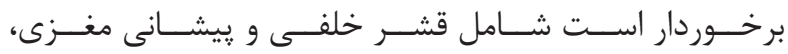

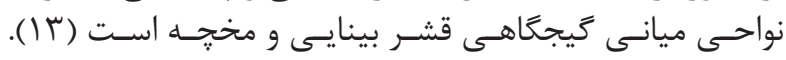

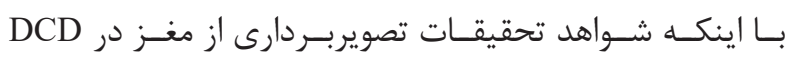

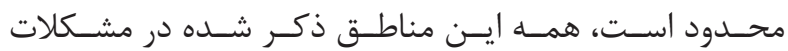

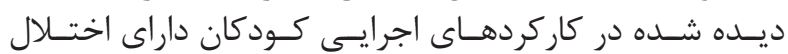

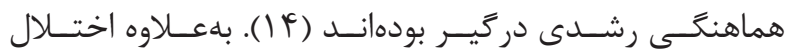

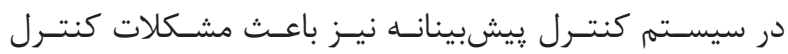

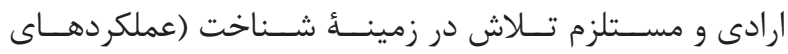

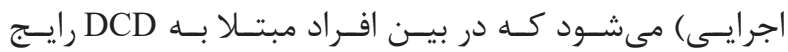

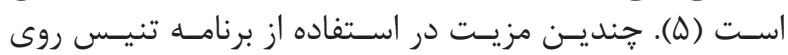

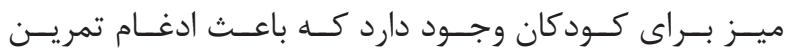

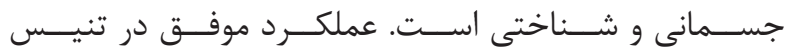

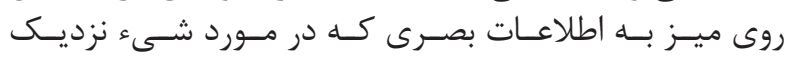

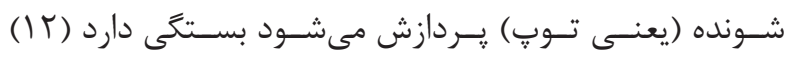

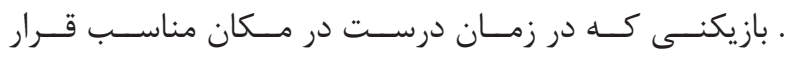

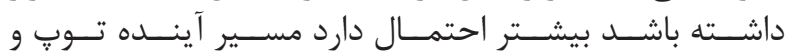

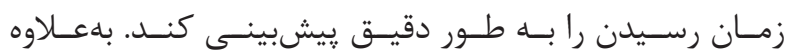

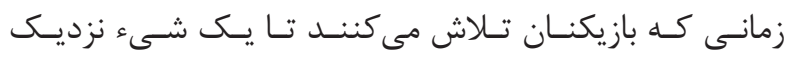

${ }^{7}$ Developmental coordination disorder Questionnaire; DCDQ07 ${ }^{8}$ Wilson 


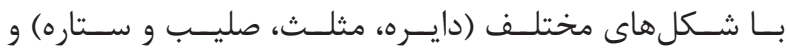

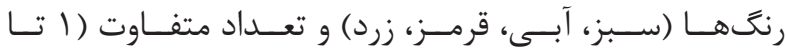

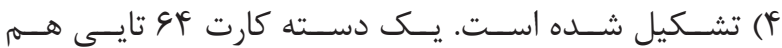

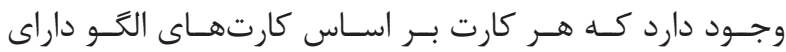

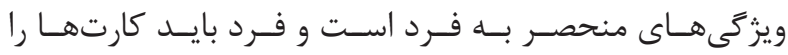

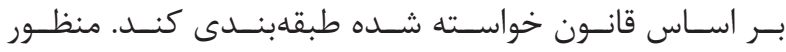

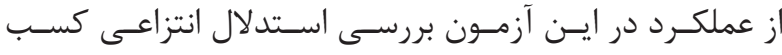

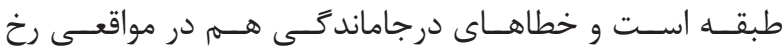

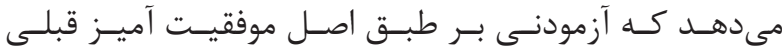

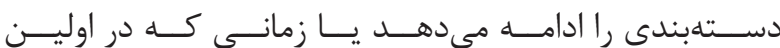

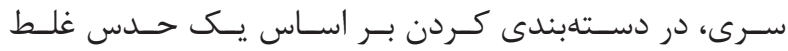

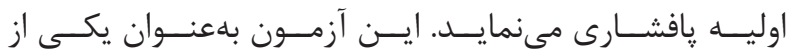

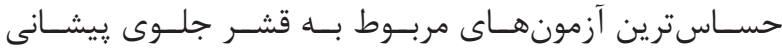

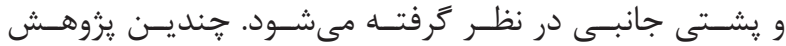

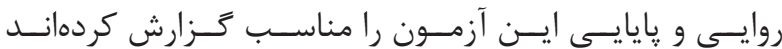

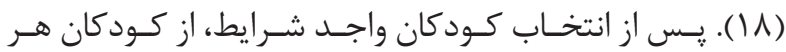

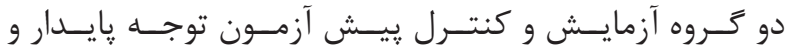

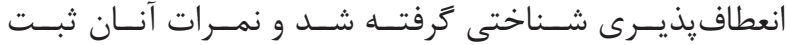

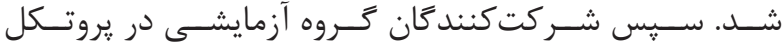

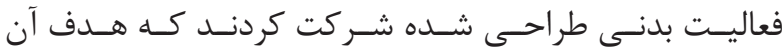

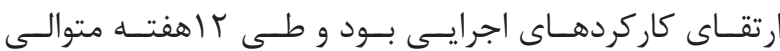

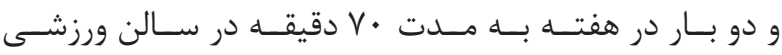

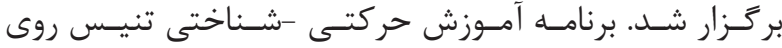

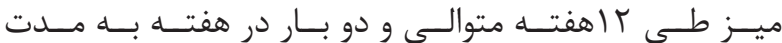

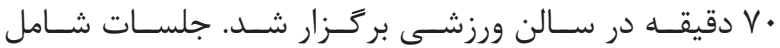

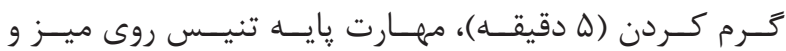

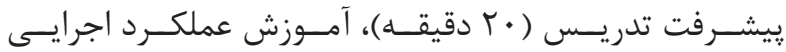

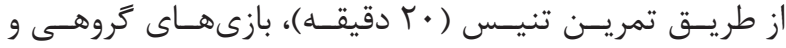

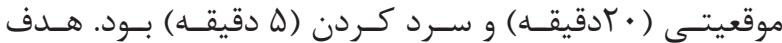

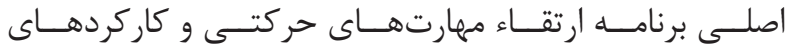

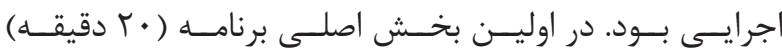

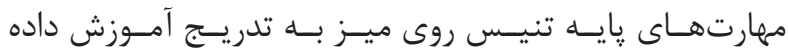

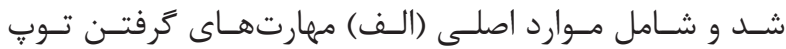

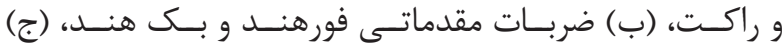

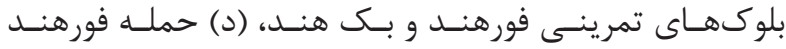

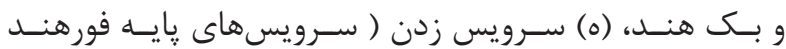

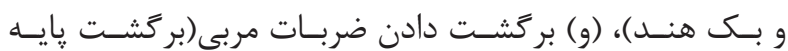

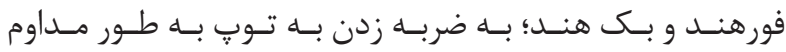

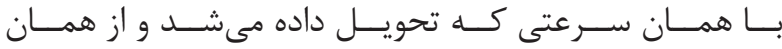

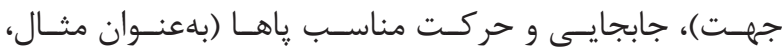

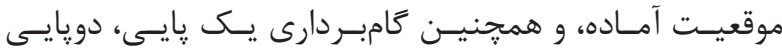

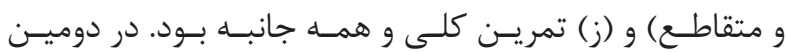

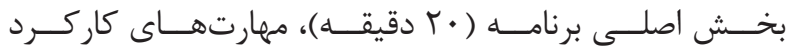

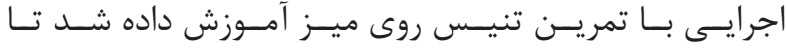

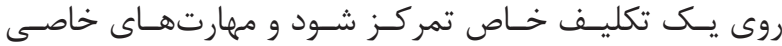

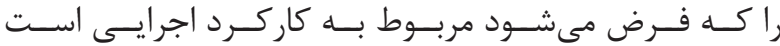

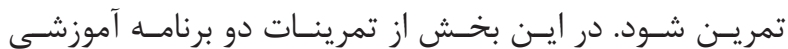

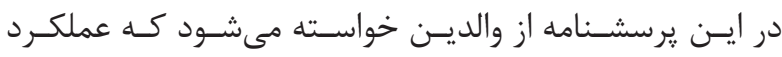

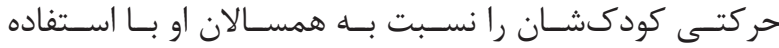

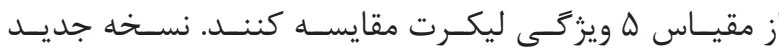

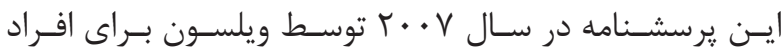

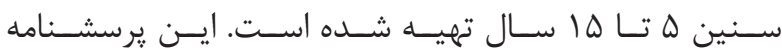

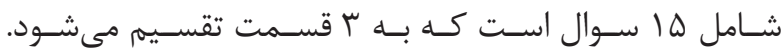

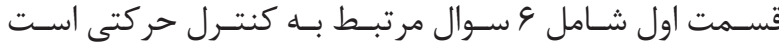

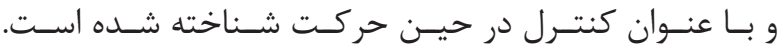

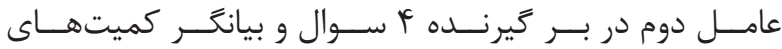

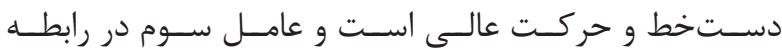

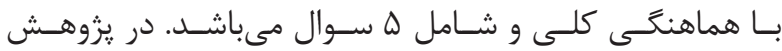

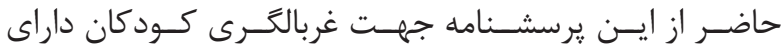

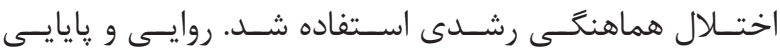

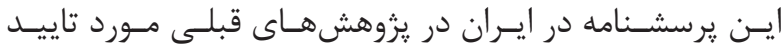

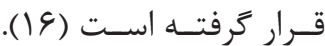

ابزارهاى يزوهش

آزمــون ارزيابسى حــركات جنبشـى كـود كان " (MABC-2) ايسن

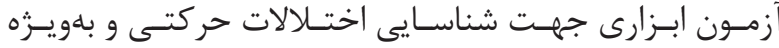

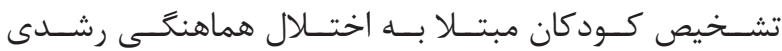

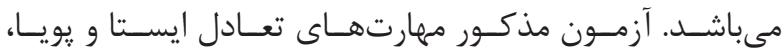

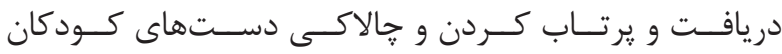

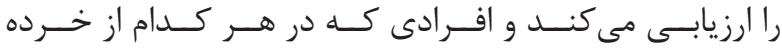

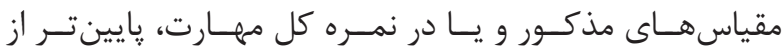

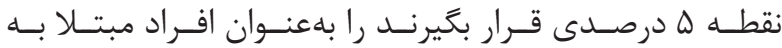

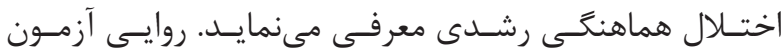

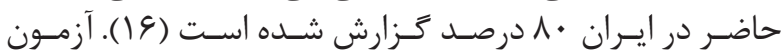

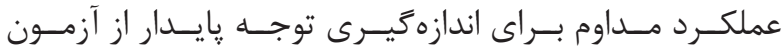

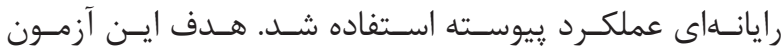

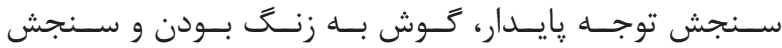

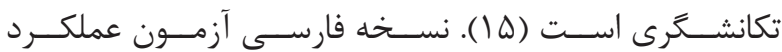

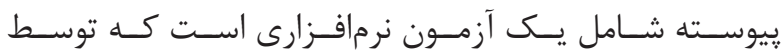

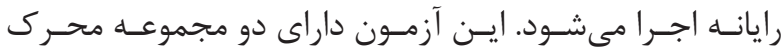

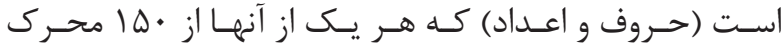

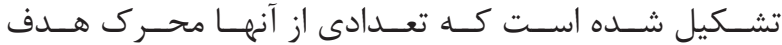

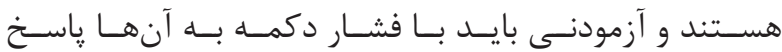

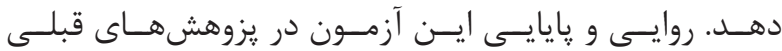

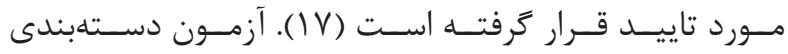

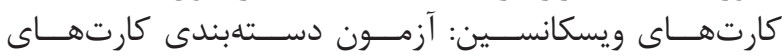

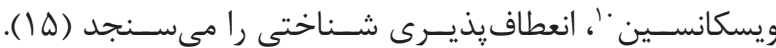

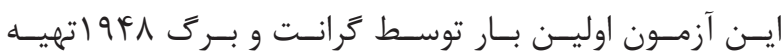

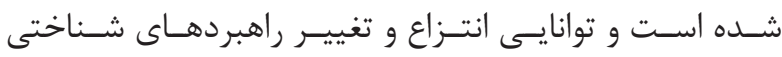

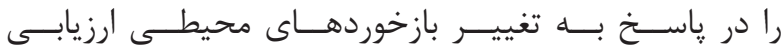

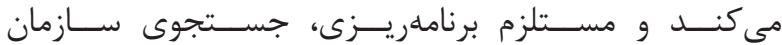

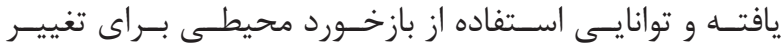

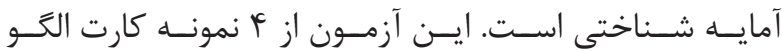

${ }^{9}$ Movement Assessment Buttery for Children; MABC-2

${ }^{10}$ Wisconsin Card Sorting Task 


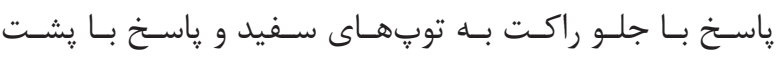

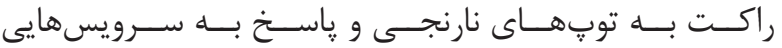

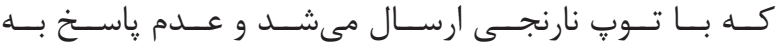

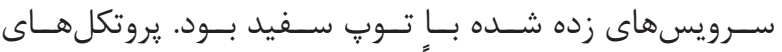

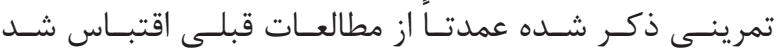

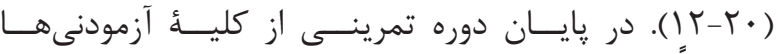

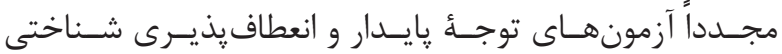

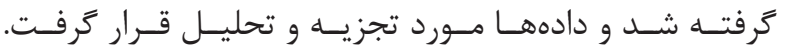

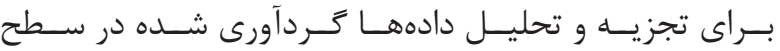

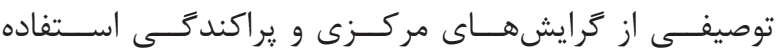

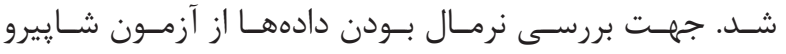

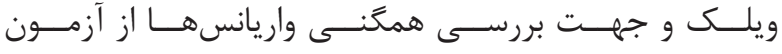

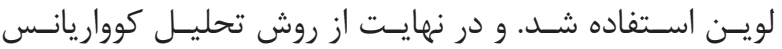

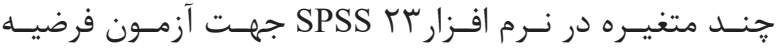

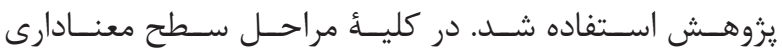

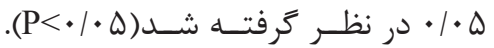

بافتهها

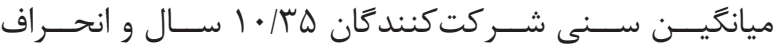

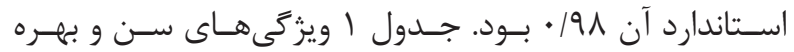

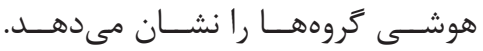

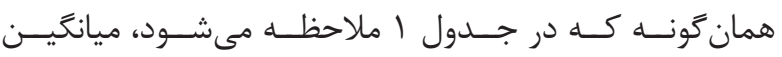

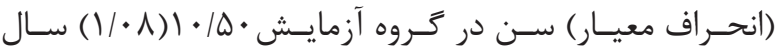

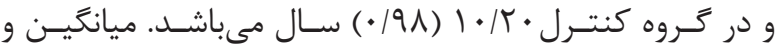

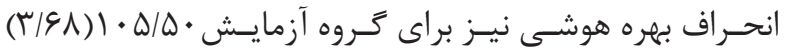

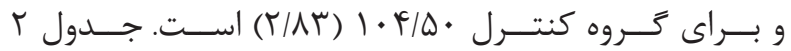

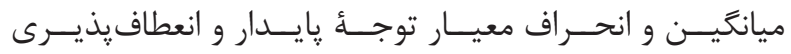

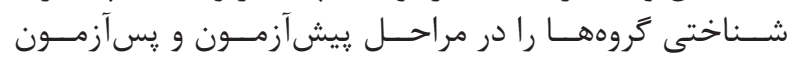

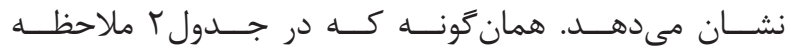

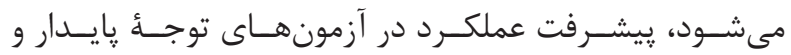

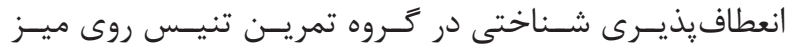

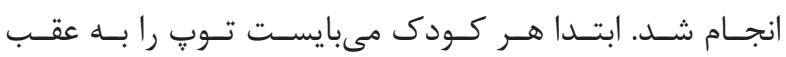

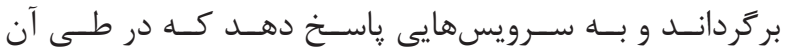

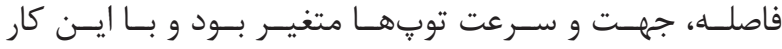

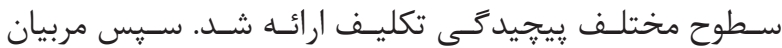

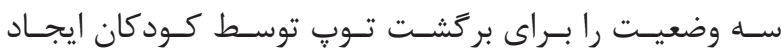

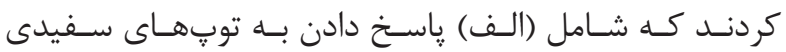

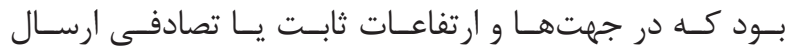

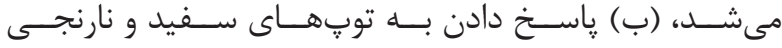

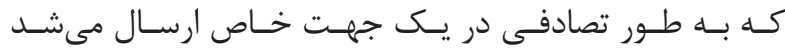

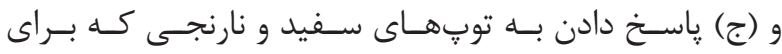

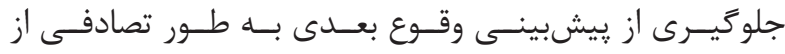

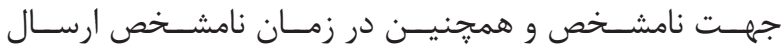

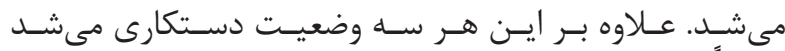

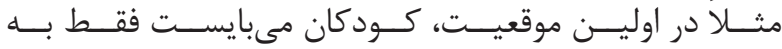

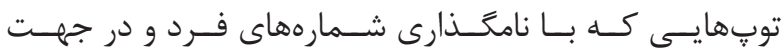

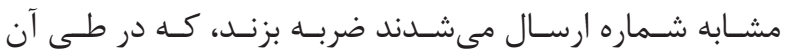

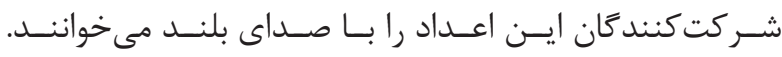

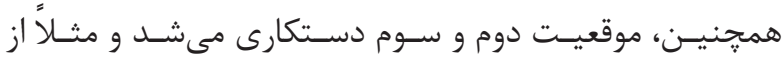

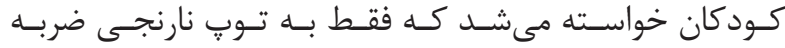

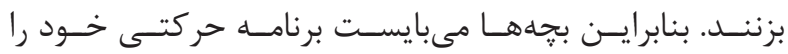

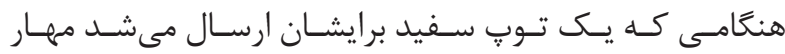

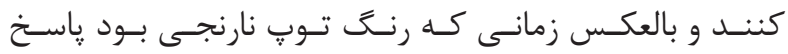

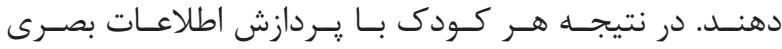

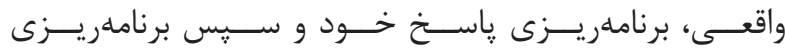

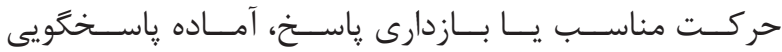

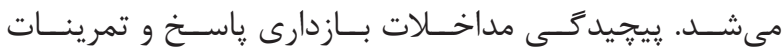

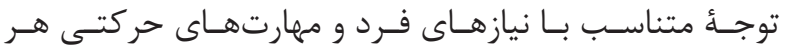

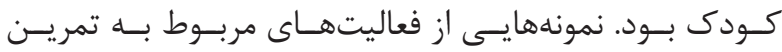

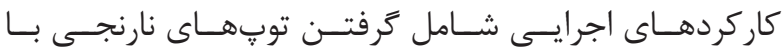

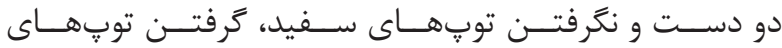

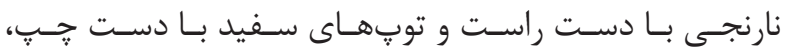

جدول ا- ميانگين و انحراف معيار مربوط به سن و بجره هوشى در نمونأ مورد يُوهش

\begin{tabular}{|c|c|c|c|c|}
\hline \multicolumn{2}{|c|}{ هوشجير } & \multicolumn{2}{|c|}{ سن } & \multirow{2}{*}{ تروه } \\
\hline انحر اف معيار & ميانگين & انحر اف معيار & ميانگين & \\
\hline r/91 & $1 \cdot \Delta / \Delta \cdot$ & $1 / \cdot 1$ & $1 \cdot 10$. & آزمايش \\
\hline r/Ar & $1 \cdot \boldsymbol{F} / \Delta$ & .191 & $1 \cdot / r$. & تروه كنترل \\
\hline
\end{tabular}




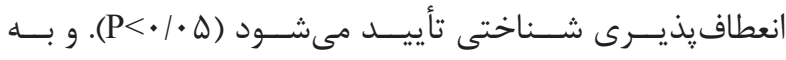

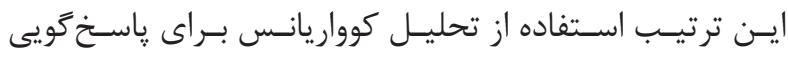

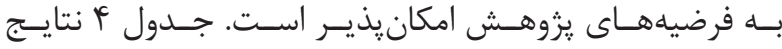

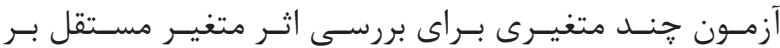

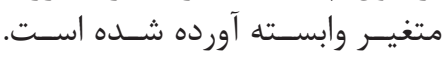

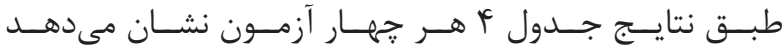

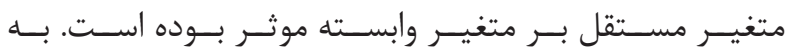

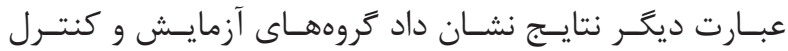

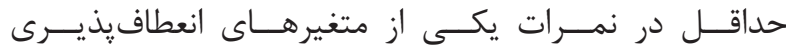

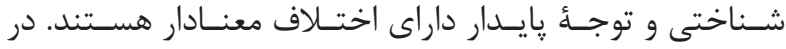

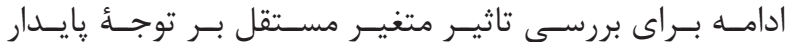

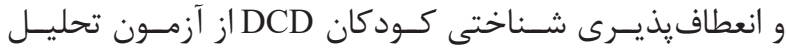

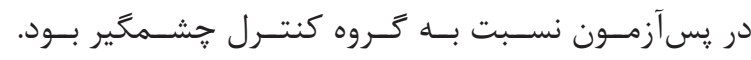

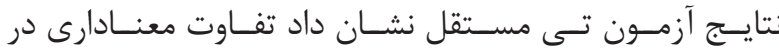

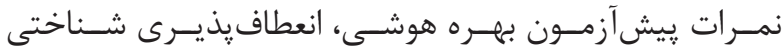

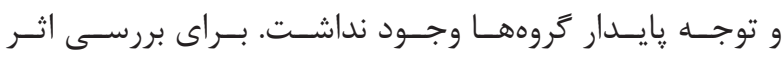

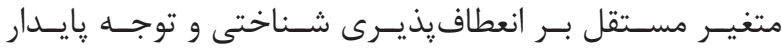

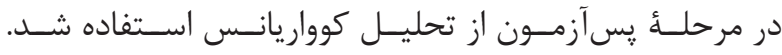

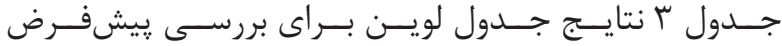

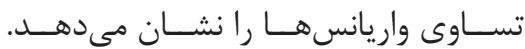

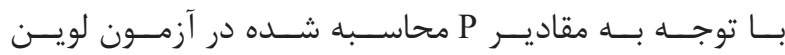

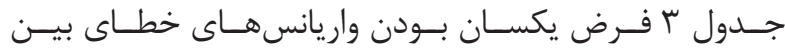

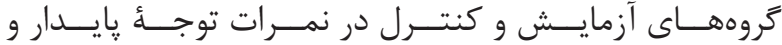

جدول r- ميانكَين و انحراف معيار توجئ بايدار و انعطاف يذيرى شناختى در در دو كَروه در بيش آزمون و پِّآزمون

\begin{tabular}{|c|c|c|c|c|c|}
\hline \multicolumn{2}{|c|}{ 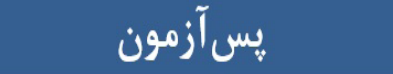 } & \multicolumn{2}{|c|}{ ي بيش آزمون } & \multirow{2}{*}{ 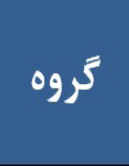 } & \multirow{2}{*}{ متغير } \\
\hline انحر اف معيار & ميانكين & انحر اف معيار & 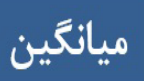 & & \\
\hline$\Delta / / V$ & $|r \varphi| 1$ & 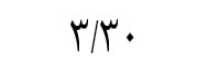 & $\mid Y K / D$ & 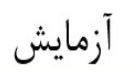 & \multirow{2}{*}{ توجهُ هايدار } \\
\hline$\Delta / 1 \Lambda$ & $\mid r y / \cdots$ & F/TG & $\mid r M / \Lambda$. & 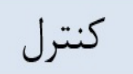 & \\
\hline$\cdot \mid \uparrow \wedge$ & $1 / V$ & $\cdot / V^{\mu}$ & $\Delta / 1 \cdot$ & 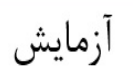 & \multirow{2}{*}{ انعطاف يذيرى شناختى(خطا) } \\
\hline$\cdot \operatorname{dar}$ & $\varepsilon / \Delta$ & $\cdot / \mathrm{V} \Lambda$ & $\boldsymbol{c} / \Lambda$ & 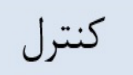 & \\
\hline$\cdot \mid \uparrow \wedge$ & $r / \mu \cdot$ & $\cdot|0|$ & $\Delta / 9$. & 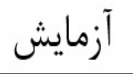 & \multirow{2}{*}{ انعطاف يذيرى شناختى(درجاماندكى } \\
\hline $.19 \mu$ & $\Delta / r \cdot$ & $\cdot 19 \mathrm{~V}$ & $\Delta / \mathrm{V} \cdot$ & 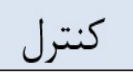 & \\
\hline
\end{tabular}

جدول ب- نتايج آزمون لوين در مورد يِيش فرض تساوى واريانسها

\begin{tabular}{|c|c|c|c|c|}
\hline \multicolumn{5}{|c|}{ لوين } \\
\hline سطح معنادارى & F & درجهُ آزادى ب & درجهُ آزادى ا & متغير \\
\hline .1994 &.$/ 19$. & 11 & 1 & توجهُ هايدار \\
\hline$\cdot / r \cdot V$ & $I / V I F$ & 11 & 1 & انعطاف يذيرى شناختى(خطا) \\
\hline$\cdot 1991$ &.$/ 199$ & 11 & 1 & انعطاف يذيرى شناختى(درجاماندگى) \\
\hline
\end{tabular}

جدول F- آزمون فرض لامبداى ويلكز براى تأييد فرض جند متغيره

\begin{tabular}{|c|c|c|c|c|c|c|}
\hline مجنور اتا & سطح معنادارى & درجهُ آزادى & F & تخمين & \multicolumn{2}{|l|}{ متغير آزمون } \\
\hline $.19 \Delta f$ & $\cdot 1 \cdot \cdot 1$ & r & $111 / 901$ & $\cdot / 9 \Delta F$ & رديابى بيلايى & \multirow{4}{*}{ تروه } \\
\hline$\cdot 19 \Delta F$ & $\cdot 1 \cdot \cdot 1$ & r & $111 / 901$ & $\cdot 1 \cdot p q$ & ويلكز لامبدا & \\
\hline$\cdot 19 \Delta F$ & $\cdot 1 \cdot \cdot 1$ & r & $111 / 901$ & $r \cdot 19 \mu r$ & اثر هتللينك & \\
\hline.$/ 9 \Delta F$ & $\cdot 1 \cdot \cdot 1$ & r & $111 / 901$ & $r \cdot 19 \mu r$ & بزرَترين ريشه روى & \\
\hline
\end{tabular}




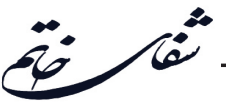

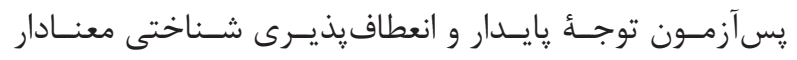

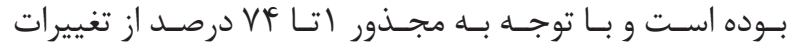

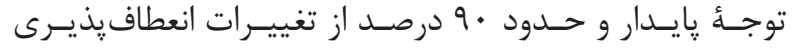

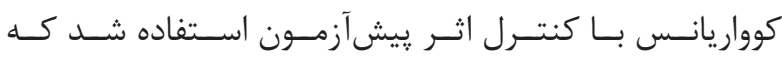

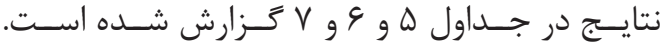

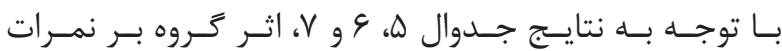

\begin{tabular}{|c|c|c|c|c|c|c|}
\hline ضريب اتا & سطح معنادارى & نسبت F F & ميانكين مجذورات & درجهُ آزادى & مجموع مجذورات & منبع تفييرات \\
\hline - laf. & $.1 . .1$ & 19/9V9 & $r q \cdot / 9 \cdot 1$ & 1 & $r q \cdot 19 \cdot 1$ & ييش آزمون \\
\hline . NFF & $.1 . .1$ & rq/rir & $94 \% / 994$ & 1 & $944 / 994$ & 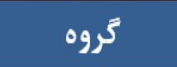 \\
\hline & & & $1 \% / \cdot 09$ & IV & TrI/999 & خطا \\
\hline 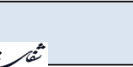 & & & & $r$. & rrqeva & مجموع \\
\hline
\end{tabular}

جدول 9- نتايج آزمون تحليل كوواريانس براى مقايسه انعطاف يذيرى شناختى (خطا) در كروهها

\begin{tabular}{|c|c|c|c|c|c|c|}
\hline ضريب اتا & سطح معنادارى & نسبت F & ميانكين مجذورات & درجه آزادى & مجموع مجذورات & منبع تغييرات \\
\hline - Kra &.$/ \cdot f$. & $f / q f q$ & $1 / \cdot r V$ & 1 & $1 / \cdot r V$ & بيش آزمون \\
\hline .1919 & $\cdot 1 \cdot \cdot 1$ & 191/94V & $f \cdot / 194$ & 1 & $f \cdot / 19 r$ & تروه \\
\hline & & & $\cdot|r| \cdot$ & IV & r/DGr & خطا \\
\hline & & & & $r$. & TrG & مجموع \\
\hline
\end{tabular}

جدول V- نتايج آزمون تحليل كوواريانس براى مقايسه انعطاف يذيرى شناختى (درجاماندكى) در كروهها

\begin{tabular}{|c|c|c|c|c|c|c|}
\hline ضريب اتا & سطح معنادارى & نسبت F & ميانكين مجذورات & درجه آزادى & مجموع مجذورات & منبع تغييرات \\
\hline$\cdot / \cdot \Delta r$ & - MFF & $.194 \wedge$ & $\cdot / \mu \cdot 1$ & 1 & $\cdot / \mu \cdot 1$ & هيش آزمون \\
\hline \multirow[t]{3}{*}{$\cdot / \Lambda \Lambda \Delta$} & $\cdot 1 \cdot \cdot 1$ & 11.1999 & $f 1 / 0.9$ & 1 & $41 / 0.9$ & تروه \\
\hline & & & $\cdot / \mu 11$ & IV & Q/ & خطا \\
\hline & & & & $r$. & r & مجموع \\
\hline
\end{tabular}

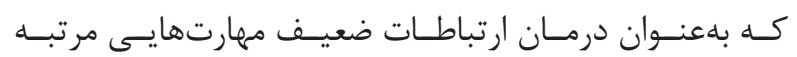

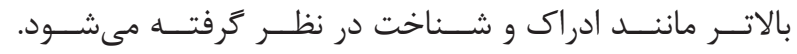

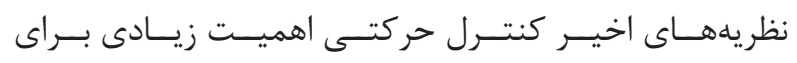

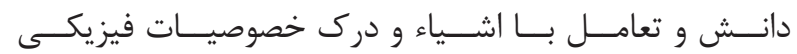

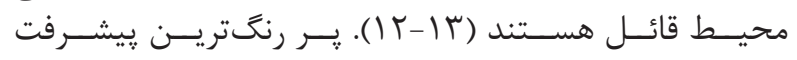

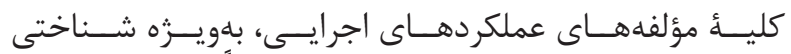

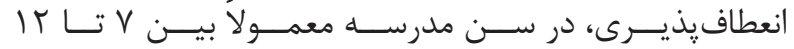

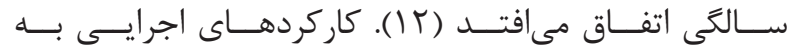

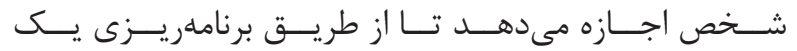

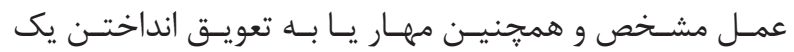

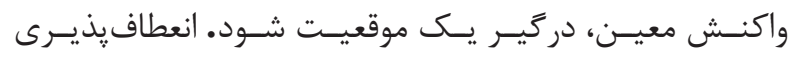

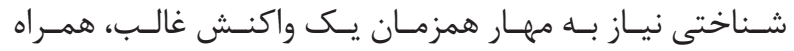

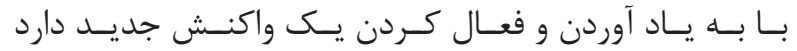

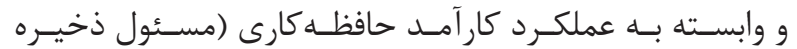

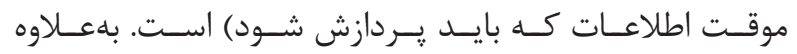

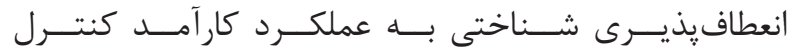

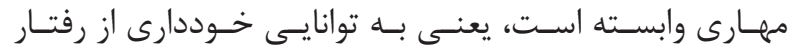

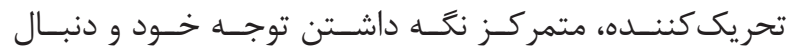

شــاختى ناشـى از تاثيـر تمرينــات بـوده اسـت. بحث و نتيجه كيرى

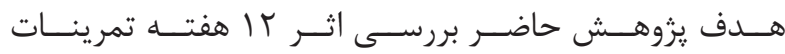

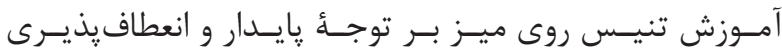

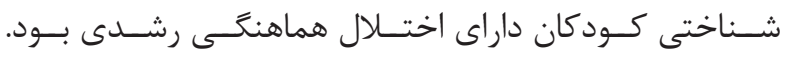

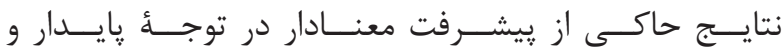

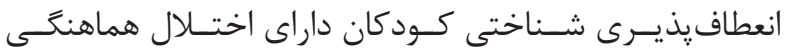

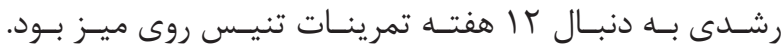

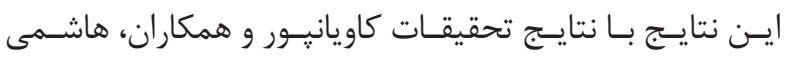

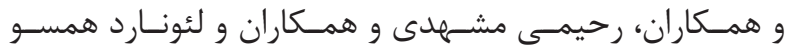

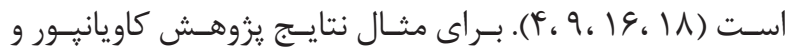

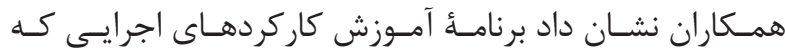

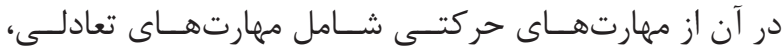

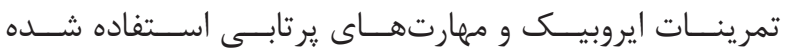

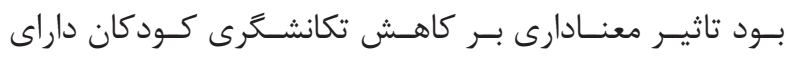

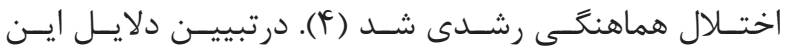

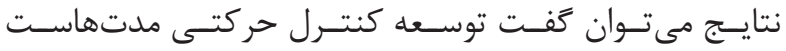




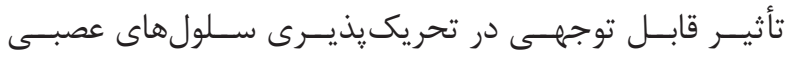

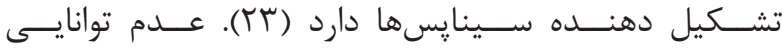

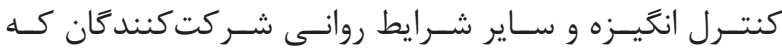

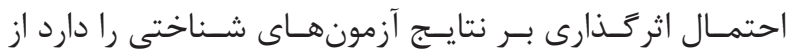

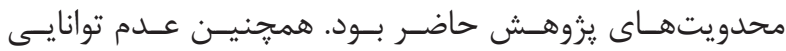

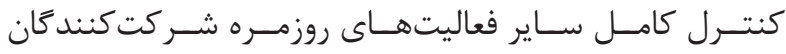

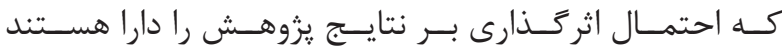

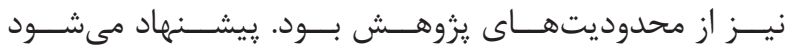

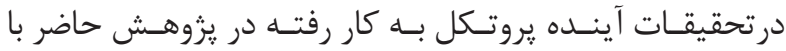

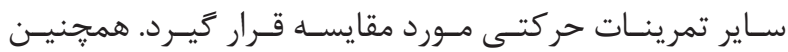

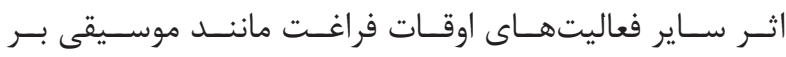

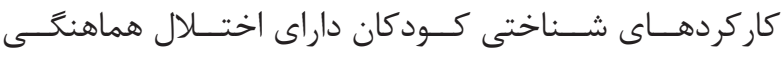

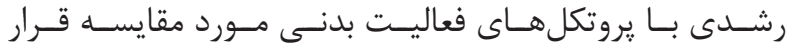

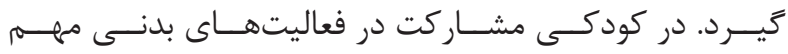

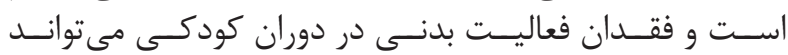

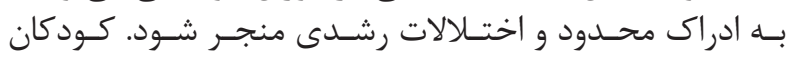

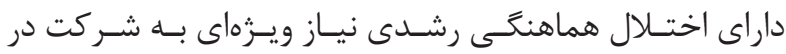

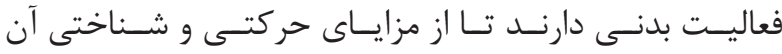

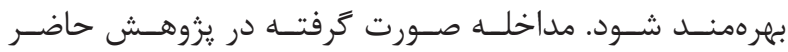

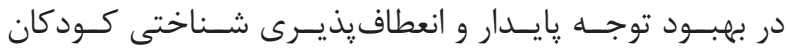

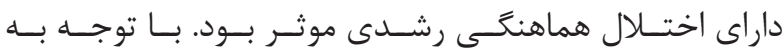

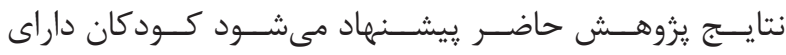

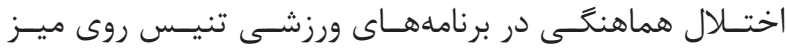

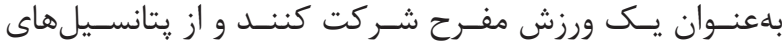

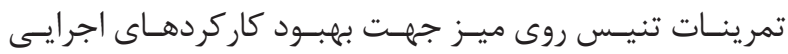

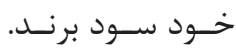

$$
\text { تشكر و قدردانى }
$$

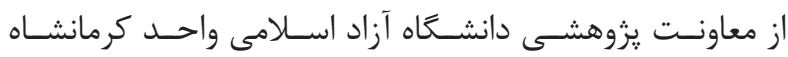

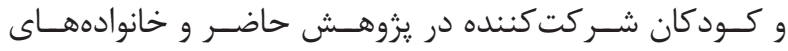

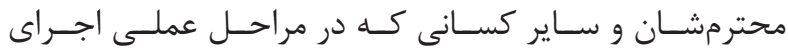

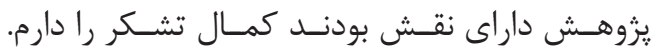

1. Bernardi M, Leonard HC, Hill EL, Botting N, Henry LA. Executive functions in children with developmental coordination disorder: a 2-year follow-up study. Dev Med Child Neurol. 2018; 60(3): 306-13.

2. Jahanbakhsh H, sohrabi m, Saberi Kakhki A, khodashenas E. The effect of a selected training program under dual-task and single-task conditions on the cognitive flexibility of children with developmental coordination disability. Psychology of Exceptional Individuals. 2019; 9(34): 31-49.

3. Fong SSM, Chung JWY, Cheng YTY, Yam TTT, Chiu $\mathrm{H}-\mathrm{C}$, Fong DYT, et al. Attention during functional tasks is associated with motor performance in children with

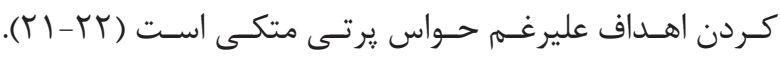

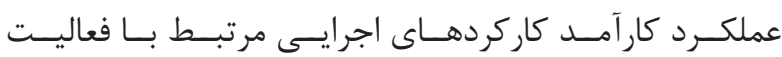

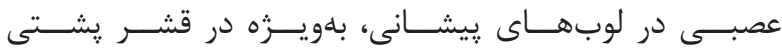

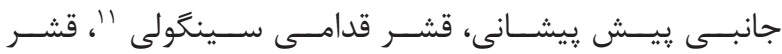

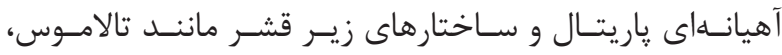

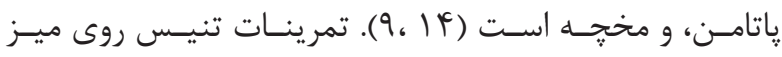

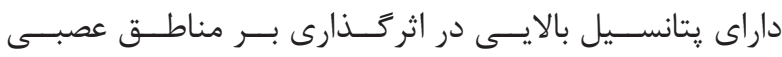

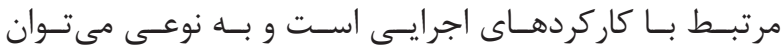

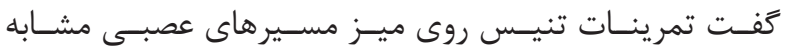

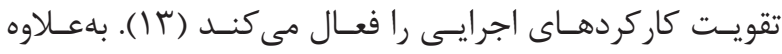

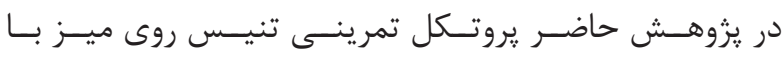

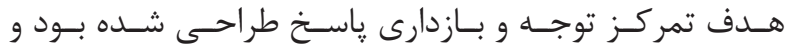

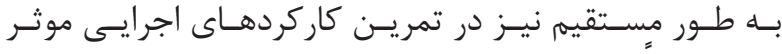

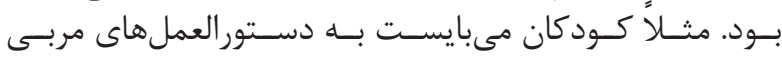

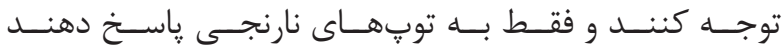

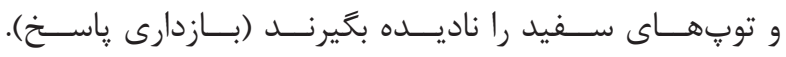

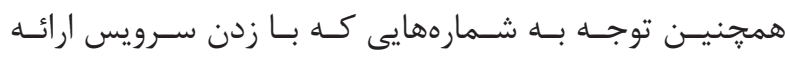

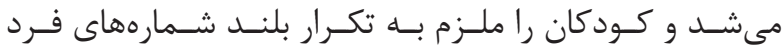

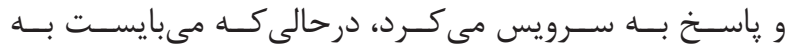

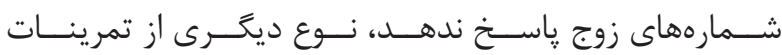

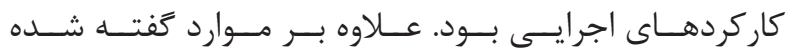

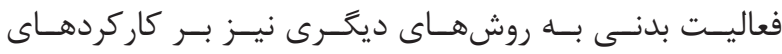

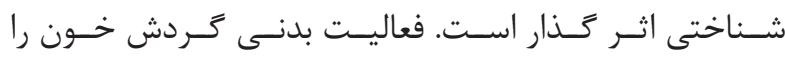

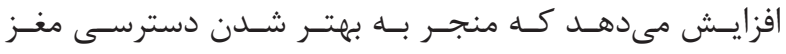

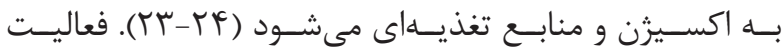

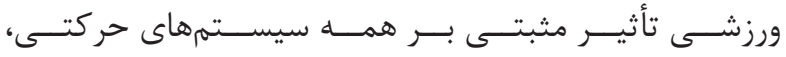

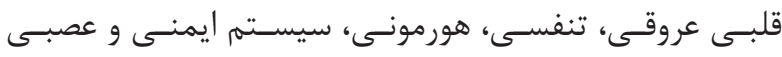

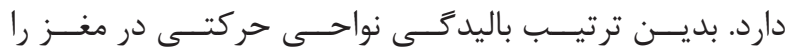

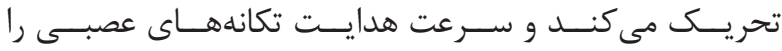

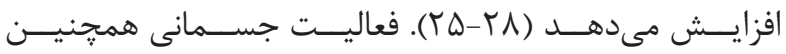

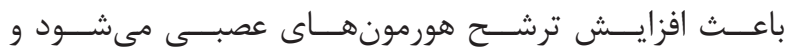

منابع developmental coordination disorder: A cross-sectional study. Medicine (Baltimore). 2016; 95(37): 35-42.

4. Kavianpour F, Malekpour M, A'bedi A. Efficacy of Executive Functions Training (Response Inhibition) on the Rate of Impulsivity in Preschool Children with Developmental Coordination Disorder: A Single-Subject Research. jrehab. 2013; 14(1): 70-80.

5. Leonard HC, Hill EL. Executive Difficulties in Developmental Coordination Disorder: Methodological Issues and Future Directions. Current Developmental Disorders Reports. 2015; 2(2): 141-9.

6. Ahmadi A, Arjmandnia AA, Azizi MP, motie S. 


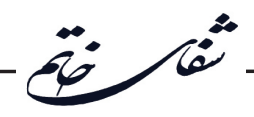

The Effectiveness of Computer-Based Executive Function Training on Cognitive Characteristic and Math Achievement of Children with Attention Deficit Hyperactivity Disorder. Journal of Pediatric Nursing. 2017; 4(1): 43-50.

7. Khaksar Boldaji MA, Abdollahi MH, Kadivar P, Hasan Abadi HR, Arjomandnia A. The Effectiveness of Computer-based Cognitive Training on WorkingMemory on Attention, Response Control, and Central Executive of Working Memory of Children with Specific Learning Disabilities. Social Cognition. 2018; 7(2): 173-86.

8. Diamond A. Close Interrelation of Motor Development and Cognitive Development and of the Cerebellum and Prefrontal Cortex. Child Development. 2000; 71(1): 44-56.

9. Leonard HC. The Impact of Poor Motor Skills on Perceptual, Social and Cognitive Development: The Case of Developmental Coordination Disorder. Front Psychol. 2016; 7: 311-21.

10. Shahrbanian S, Hashemi A. The Effects of Core Stabilization Training on Balance and Reaction Time in Children with Developmental Coordination Disorder. jrsm. 2018;8(16):83-91.

11. Kalkhoran JF, Amini HA, Salman ZI, Zareiyan E. Gymnastics Training Improves Executive and Sensorimotor Functions in Children with Developmental Coordination Disorder. Journal of Integrative Pediatric Healthcare. 2018; 2(1): 1-6.

12. Pan C-Y, Tsai C-L, Chu C-H, Sung M-C, Huang $\mathrm{C}-\mathrm{Y}, \mathrm{Ma} \mathrm{W}-\mathrm{Y}$. Effects of physical exercise intervention on motor skills and executive functions in children with ADHD: A pilot study. Journal of attention disorders. 2019; 23(4): 384-97.

13. Von Hofsten C. An action perspective on motor development. Trends in cognitive sciences. 2004; 8(6): 266-72.

14. Zwicker JG, Missiuna C, Boyd LA. Neural correlates of developmental coordination disorder: a review of hypotheses. J Child Neurol. 2009; 24(10): 1273-81.

15. Gomez R, Vance A, Watson SD. Structure of the Wechsler Intelligence Scale for Children-Fourth Edition in a group of children with ADHD. Frontiers in Psychology. 2016; 7: 737-48.
16. Hashemi A, Sheikh M, Homaneyan D, Bagherzaeh F. The effect of Wii Fit training on metacognitive characteristics of children with developmental coordination disorder. journal of motor and behavioral sciences. 2019; 2(3): 177-88.

17. Abdi A, Arabani Dana ALI, Hatami J, Parand A. The effect of cognitive computer games on working memoty, attention and cognitive flexibility in students with attentional deficit hyperactivity disorder. Journal of exeptional children. 2014; 19-33.

18. Rahimianmashhadi M, Shamsipoordehkordi P. The Effect of Cognitive Rehabilitation Training and Progressive Physical Training on Cognitive Flexibility and Social Developmental on Mentally Retarded Children. Neuropsychology. 2018; 4(14): 91-110.

19. Tsai C-L. The effectiveness of exercise intervention on inhibitory control in children with developmental coordination disorder: Using a visuospatial attention paradigm as a model. Research in Developmental Disabilities. 2009; 30(6): 1268-80.

20. Tsai C-L, Wang C-H, Tseng Y-T. Effects of exercise intervention on event-related potential and task performance indices of attention networks in children with developmental coordination disorder. Brain and cognition. 2012; 79(1): 12-22.

21. Houghton G, Tipper SP. Inhibitory mechanisms of neural and cognitive control: Applications to selective attention and sequential action. Brain and Cognition. 1996; 30(1): 20-43.

22. Jodzio K. Neuropsychologia intencjonalnego działania: koncepcje funkcji wykonawczych: Wydawnictwo Naukowe Scholar; 2008.

23. Hollmann W, Strüder H. Brain, psyche and physical activity. Der Orthopade. 2000; 29(11): 948-56.

24. Makarowski R, Lipowski M, Marszałł M, Czarnowski W. Temperamental determinants of physical activity as preventive factor of heart diseases-In the search of the model. Pol J Sport Med. 2009; 25: 83-94.

25. Alesi M, Bianco A, Padulo J, Vella FP, Petrucci M, Paoli A, et al. Motor and cognitive development: the role of karate. Muscles Ligaments Tendons J. 2014; 4(2): 114-20. 
26. van der Fels IM, Te Wierike SC, Hartman E, ElferinkGemser MT, Smith J, Visscher C. The relationship between motor skills and cognitive skills in 4-16 year old typically developing children: A systematic review. Journal of science and medicine in sport. 2015; 18(6): 697-703.

27. Biddle SJ, Gorely T, Stensel DJ. Health-enhancing physical activity and sedentary behaviour in children and adolescents. Journal of sports sciences. 2004; 22(8): 679-701.

28. Janssen I, LeBlanc AG. Systematic review of the health benefits of physical activity and fitness in school-aged children and youth. International journal of behavioral nutrition and physical activity. 2010; 7(1): 40 